Tutorial

\title{
New uses for computer in medical education, clinical practice, and patient safety in the US and Japan
}

\author{
Daisuke KOIDE ${ }^{1}$ and Edward PESKIN, MD² \\ ${ }^{1}$ Clinical Bioinformatics Research Unit, Graduate School of Medicine, Univ. of Tokyo \\ ${ }^{2}$ General Obstetrics and Gynecology, Medical School, Univ. of Massachusetts
}

\begin{abstract}
There has been a rapid expansion of computer use in medicine recently in the US and Japan. The reasons are availability of high speed and wireless connections, decreasing cost, demands for increased quality of care and documentation, and improving medical education. On the other hand, there are disadvantages which are extra time and effort needed, vulnerability to viruses, breaches of patient confidentiality, and high cost at start-up.

One way to decide if the advantages of computers in medicine overcome the disadvantages to show physicians computer programs that may be useful to them. There are many such programs in Japanese as well as in English which are discussed in this paper.

A major difference between the US and Japan is the high use of personalized digital assistants (PDAs) by US physicians as compared to Japanese physicians. PDAs can decrease medical errors due to rapid information access while improving efficiency.

Although the market for the PDAs is currently decreasing in Japan, the coming merger of the cell phone and the PDA into the "smart phone" is likely to stimulate Japanese physicians' interest in PDAs for medical use, especially considering the widespread popularity of cellular phones in Japan.
\end{abstract}

\section{KEYWORDS}

Computer, personal digital assistance (PDA), medical education, clinical practice, patient safety, smart phone

\section{Introduction \\ 1.1 Computerization in the field of medicine in Japan}

The history of computerization in medicine started in 70s. [1] At that time, the main purpose of computerization was labor-saving for the process of insurance claim and the scope was limited only within administrative section in medical institutions. The physician order entry system (POES) appeared in 80 s by a centralized system of a host computer and based on the computerization of clinical laboratory and pharmacy. [2] The POES contributed reducing patient's waiting time in clinical institutions and also making the process of insurance claim efficient. The growth of networking, especially the Internet in 90s enhanced coop-

Received July 26, 2005; Revised September 6, 2005; Accepted Sepember 7, 2005.

Koide-tky@umin.ac.jp

2) peskin@ummhc.org

DOI : 10.2201/NiiPi.2005.2.2 eration among clinical professionals or clinical institutions. [3] Also, the electronic medical record (EMR) came into realistic and a hospital in the west of Japan implemented EMR and got rid of paper first in 1999. [4]

In 2001, Japanese government established e-Japan policy, and health care and social welfare is one of the main target fields. [5] Then, the ministry of health labor and welfare (MHLW) published "IT ground design for healthcare system" in the end of 2001. It focused on EMR and the national standard software for electronic process of insurance claim. It made target to implement by the end of 2006; over $60 \%$ of institutions which has more than 400 beds should install EMR and over $70 \%$ of institutions should install the national standard software for electronic process of insurance claim. [6] According to the survey by the MHLW in 2002, [7] only $1.3 \%$ out of total 
8,023 hospitals have EMR and $15.3 \%$ have the POES. It is also only $2.3 \%$ that the percentage of hospitals installed the national standard software for electronic process of insurance claim. However, such numbers are dramatically increasing recently.

As overall, computers are very popular among Japanese people and international survey in 2003 [8] showed that $38 \%$ had laptop or desktop computers in 2002 and $68 \%$ had a mobile phone in 2003 in Japan. The corresponding numbers for the US were $66 \%$ and $54 \%$. The percentage of the Internet users were $45 \%$ for Japan and $55 \%$ for the US in 2002 (ITU Telecommunication Indicators).

\subsection{Computerization in the field of medicine in the US}

There has been a rapid expansion of computer use in medicine recently in the US for a number of uses including medical education at all levels, point of service medical information (especially diagnostic, treatment, and medications), medical research, EMRs, electronic billing, electronic prescribing, and the collection of data to determine quality of care and quality of medical education.

Some possible reasons why computers are increasingly used in US medical care are availability of high speed connections, availability of personal digital assistants (PDAs), availability of wireless connections, decreasing cost of hardware and software, public and government demands for increased quality of care and documentation of that quality, too much information to process without electronic help.

Wireless LANs are much more common today in hospitals than in doctors' offices. Only about 8 percent of physician practices have gone wireless. By comparison, 61 percent of integrated delivery networks and 36 percent of stand-alone hospitals have some wireless capability in the US. [9]

In terms of security, wireless network should be protected, at least, by a combination of wireless-specific ways such as WPA/EAP according to IEEE802.1X with IPSec/VPN technologies. In addition, a separation of traffic by creating VLANs, and installation of a firewall between wired and wireless networks tightened the security of the WPA/EAP-equipped wireless networks. [10]

\section{The advantages and disadvantages of using the computer in medicine}

How can computers improve quality of care and document that quality? They can avoid illegible handwriting, can be programmed to find errors in dosage, medication name, medication interactions, and identifying allergic patients or the wrong patient, computerized records can be backed up and are less likely to be lost or unavailable, computerized records can more easily be transferred even over long distances, more easily collect data such as mortality or number of patients seen or types of diagnosis seen.

How can computers improve medical education? They can decrease the amount of class time where there is information transfer without interaction, increase the amount of class time available to answer questions and concentrate on confusing or difficult topics, teach medical students and residents how to efficiently get the most accurate, useful, and up to date information through computer programs. They can then use this technique for the rest of their career. Computers can decrease the amount of information needed to be memorized and reduce the chance of error due to faulty memory. Finally they can decrease the amount of time needed to read journals and books while still maintain high quality knowledge.

What are the disadvantages of computer use in medicine? They can be less useful for those physicians who cannot type quickly, take extra time and effort to get used to, create psychological discomfort with a new way of practicing medicine, be vulnerable to viruses and technical problems that risk lost of data unless backed up, be vulnerable to breaches of patient confidentiality, sometimes increase the amount of time needed to get work done, create fear that computerized data can be used by the legal system against doctors and hospitals, create the fear of making the interaction between the patient and doctor seem less personal and have high cost at start-up

\section{Useful websites for medicine}

\subsection{Japanese language websites for laptops or desktops}

One way to decide if the advantages to computers in medicine overcome the disadvantages to show physicians computer programs that may be useful to them. Some of the useful programs for free of charge are as follows:

\subsubsection{Clinical guideline}

There are about 30,000 new Japanese language medical articles published monthly. [11] It is difficult to catch up with up-to-date clinical evidence. Medical Information Network Distribution Service (Minds) http://minds.jcqhc.or.jp which is shown in Fig. 1 is run by Japan Council for Quality Health Care (JCQHC). [12] There are several clinical guidelines; such as asthma, lung cancer, diabetes, etc. These guidelines were provided some grants from the MHLW and developed by way of Evidence Based Medicine (EBM). There are two types of guideline for each disease; one is for clinical professionals and the other is for lay people. 


\subsubsection{Drug information}

Drug reference is the most frequently asked among clinical professionals and even asked by patients. Even in Japan, 1 drug on average is approved for use each week. [13] The Pharmaceuticals and Medical Devices Agency (PMDA) http://www.info.pmda.go.jp/ which is shown in Fig.2 provides electronic insert packages for prescription drugs and also rug safety information. [14] It used to be an affiliation of MHLW, however, it was incorporated since 2004 .

\subsection{English language websites for laptops or desktops}

In terms of medical education, http://www. healcentral.org is a U.S. non-profit group dedicated to promoting on-line medical education and is available to medical educators world-wide. [15] This organization gathers programs from many medical schools which are primarily in the US. Their site is in English

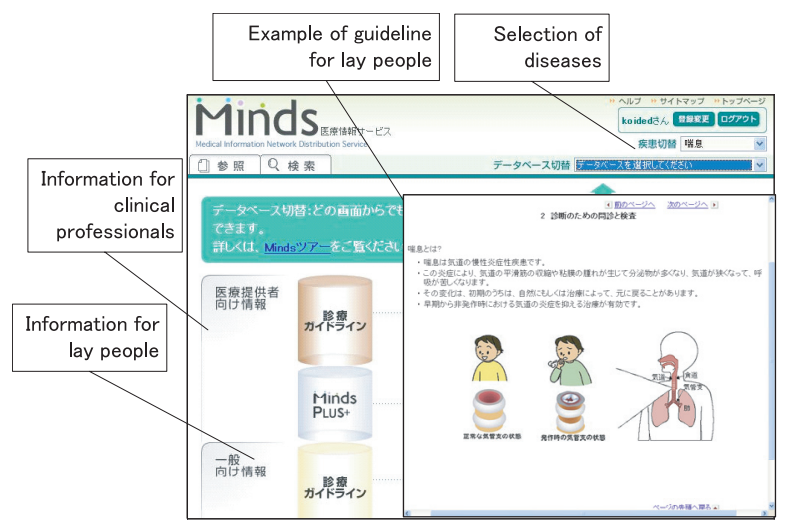

Fig.1 The guideline for asthma as an example for the site of Minds.

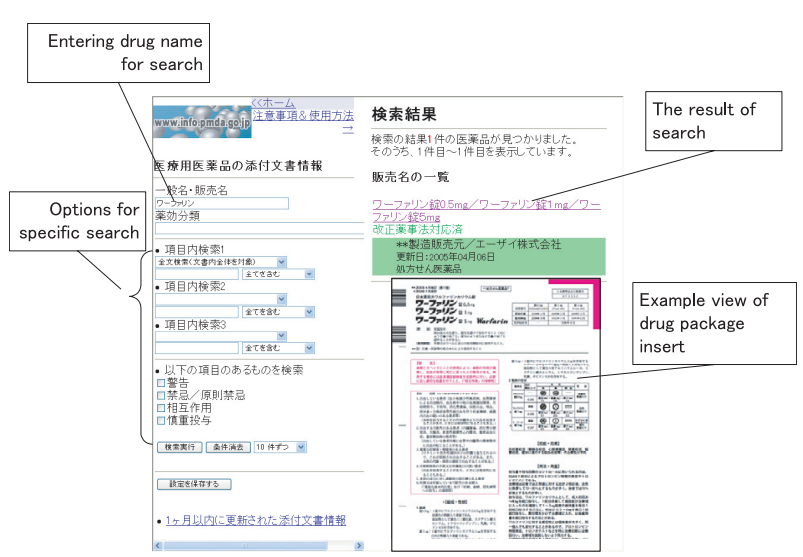

Fig.2 The webpage of PMDA and example of drug package insert. although there are some multi-lingual areas such as patient instructions written in Japanese. Healcentral.org which is shown in Fig. 3 has over 30,000 images plus videos and interactive programs. Heal information is not copy-righted and available to anyone. There are two new projects being undertaken by healcentral.org.

The first project is called heal/local and information is available at healcentral.org. It is a trial project available to any medical school or professor in the world which will personalized the heal information for that particular school or professor. More information is available at their website.

The second project was announced in June, 2005 and is a merger of healcentral.org with a large nonprofit medical education on-line learning organization in England which will add a large amount of additional content to healcentral.

In terms of clinical care, the most frequent uses of computers and PDAs by US physicians is for information gathering and, more specifically, to find drug information. A very popular but expensive program written in English is www.uptodate.com which takes no money from any outside organization and therefore claims to be free of bias. [16] It is a commercial company which hires outside experts to update its information every six months. It is a searchable data-base with information by disease or by drug. In addition, there is a program to detect drug interactions and an area for the latest developments in a specialty. It is limited to Internal Medicine and most of its subspecialties, Pediatrics, Obstetrics and Gynecology, and is adding Neurology soon. There is a PDA version of this information. An on-line introduction for up-to-date which is shown in Fig.4 is available at http:// www.uptodate.com/subscribers/tutorial/index.html.

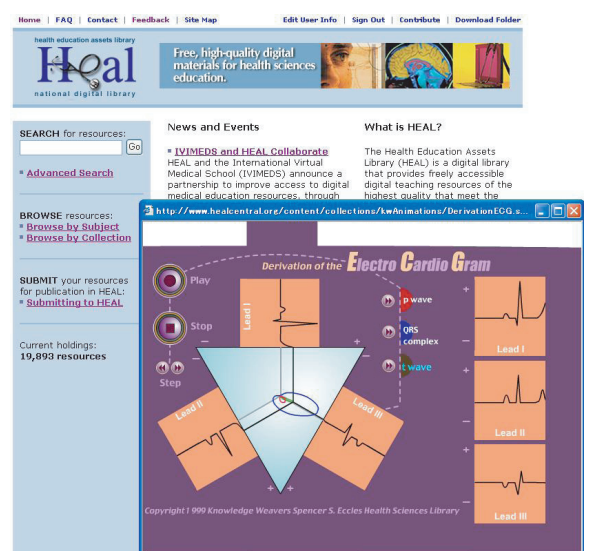

Fig.3 The webpage of Heal and an example of animation for Electro Cardio Gram. 


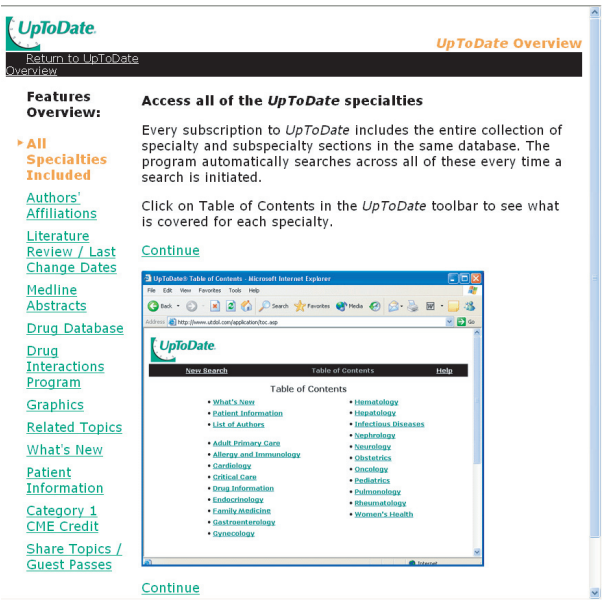

Fig.4 The webpage of introduction for Up-To-Date.

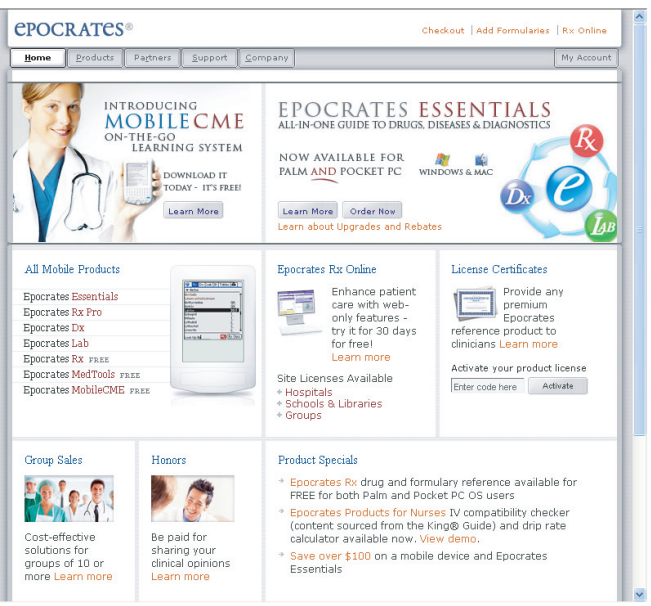

Fig.5 The webpage of epocrates.

Another program which claims to be the most popular computer program in the US is www.epocrates.com as shown in Fig.5. [17] This program is either for computer or PDA use. It is a commercial program that does receive financial support from the drug industry and therefore is very reasonably priced but at risk of bias. The key feature that distinguishes epocrates from other programs is its easy to use "multi-check" function which can find drug interactions for up to 30 medications including non-prescription medications and alternative medications such as herbs. This program is written in English only and the company does not have any immediate plans to convert it to the Japanese language. Japanese physicians were surprised to find out that there is a warning in both the epocrates and up-todate program concerning the consumption of green tea and the use of blood thinners such a warfarin since green tea also has an anti-coagulation effect. This is an example of information that would be very difficult and time consuming to get from a paper-based product.

\section{Utilization of the PDA for medicine \\ 4.1 PDA for Japanese medical professionals}

Comparing to the US, people do not use the PDAs so much in Japan. The PDAs are relatively expensive in Japan, and have the difficulty of entering Japanese characters. The cell phones are more popular than PDAs in Japan. These issues seem the reasons for minor use of PDAs in Japan. The Statistics Bureau in the ministry of internal affairs and communications in Japan published the survey of household economy of 2004, [18] and items related to information shows that the percentage of PDA ownership is $1.7 \%$. The similar figures among medical professionals can not be available. According to Japanese proceeding of Joint conference on Medical Informatics in 2004, there are only two articles about PDA out of 568. [19]

The most usage of PDA in the medical fields is for patient safety. [20] PDA with bar code reader scans ID code on a name tag of medical staff, ID code of a patient's wrist band, and bar code on a bag of intravenous drip or blood transfusion. It enables to identify what was done, who did it, when it was done, whom it was done to, why it was done, and how it was done. In other words, it can keep track of clinical process. If any mistake occurs, such as wrong blood type, wrong medication, or misidentify a patient, PDA shows warning.

In addition to patient safety, PDAs can be useful for enhancing clinical care and medical education. PDAs can be available for drug information, reference to clinical guidelines, medical dictionary, or calculations of creatininine clearance and pediatric dosage, etc. The example is shown in Fig.6. According to the information from a PDA software company, the number of downloading trial version of software from March 2005 through June 2005 are about 5,000 for drug information and clinical guidelines respectively, and about 2,000 for pediatric dosage calculation and concise medical dictionary for abbreviations. However, the number of purchase is not obtainable. The approximately $95 \%$ of the users are medical professionals and the rest of users are medical representative at pharmaceutical companies.

\subsection{PDAs for english medical professionals}

The major difference noted by the second author, who is an American physician, is the high use of mobile computer technology by U.S physicians as compared to Japanese physicians. The most commonly used mobile device in US medicine is PDA. For example, approximately $40 \%$ of US doctors use PDAs in 


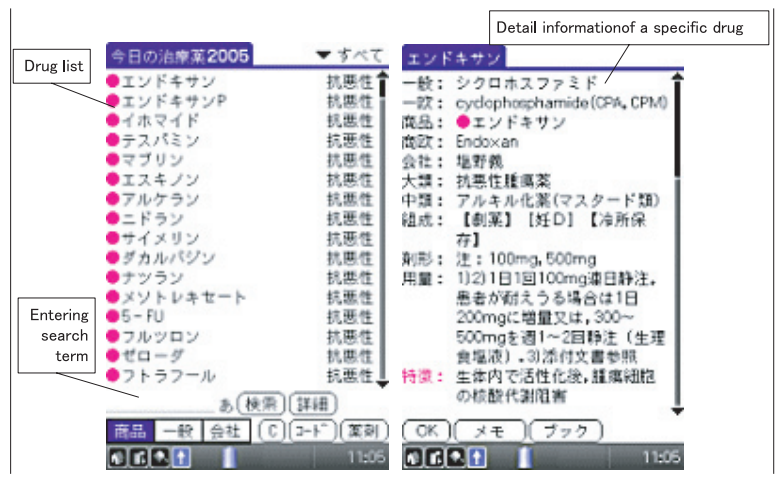

Fig.6 Drug information as an example of software for PDA.

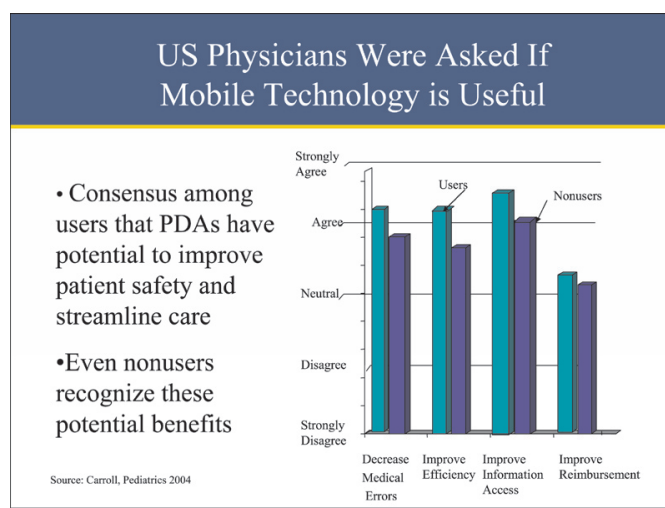

Fig. 7 Physicians' recognition about usefulness of mobile technology in the US.

2003 which was a $50 \%$ increase since 2001 . This is expected to grown to $>75 \%$ of all US physicians by 2007. Half of all members of the American College of Physicians (Specialty of Internal Medicine) were using PDAs in 2001. Specialist use of PDAs is highest among cardiologists, anesthesiologists, psychiatrists, and oncologists.

A survey of physicians using PDAs in 2002 showed that approximately $70 \%$ used them for drug reference and approximately $40 \%$ used them for scheduling. The remaining uses such as dictation, electronic prescribing, hospital interface, and other uses were approximately $20 \%$ or lower. [21]

When US physicians were asked if mobile technology is useful, the majority of users and non-users agreed that they decrease medical errors, improve efficiency, and improve information access. The result is shown in Fig.7.

In an article in The Journal of the American Medical Informatics Association in 2001, Bates reported that physicians using PDAs reported that these devices prevented an average of two adverse events. [22]

Why do PDAs improve patient safety? Insufficient drug and drug interaction information are the most common causes of serious errors and is easier to obtain quickly from a PDA. PDAs can be updated frequently so their drug information is more up to date. Multiple drug interactions are extremely difficult to determine without computer technology. PDAs can send wireless alerts with physiologic, laboratory, and medication information. PDAs can manage the transition between house staff with less chance for error. PDAs can reduce handwriting errors.

Japanese physicians may be reassured that pharmacies have computer technologies to detect drug incompatibility but errors detected after the prescription is written require extra time to correct for the pharmacist, patient, and physician. In addition, patients may sometimes go to more than one pharmacy so that interactions may not be detected.

What is the proof that PDAs improve patient safety? There is only limited information in this new field but initial reports are encouraging. For example, improvement in compliance to US national asthma guidelines in patient evaluation and drug therapy occurred after the introduction of PDAs containing these guidelines. [23] Improved documentation and patient follow-ups by emergency medicine residents was noted after the introduction of the PDA. [24] An interesting study showing that patient use of PDAs improved health was reported by Szynal in 2001 in the journal, Health Data Management. [25] The outcome measurement was improved admission condition when used by patients awaiting transplant surgery

Why do US physicians think that mobile computing improves their efficiency? When desktop computers are shared, there is extra time required for each physician to $\log$ in. This is not a problem with a personal PDA even if there is a once a day log in. In addition, PDAs do not involve the physician leaving the patient to find a computer. Furthermore, diagnostic and treatment help is available within seconds and may save lives or reduce complications if seconds are critical in patient care. Finally, PDAs are more up to date than paper books so physician does not have to look for multiple texts to get the most up to date information.

Do PDAs help promote good medical education? There is also limited data since this field is so new. One study showed use of PDAs improved learning of evidence-based medicine. [26]

\section{The future-probable merger of cell phone and the PDA in near future in both US and Japan}

Many companies providing the PDAs have been withdrawing from Japanese market, for example Handspring, IBM Japan, Palm Computing, and Sony. But recently, a new type of merging cell phone and the PDA has become a real product and its market is 
increasing in the world. Such product is called "smart phone" and some companies, for example Palm, Nokia, NTT DoCoMo have already produced such smart phones. Major OS companies for PDA are Microsoft and Palm. Furthermore, Bill Gates, chairman and chief software architect of Microsoft announced the release to manufacturing of windows mobile 5.0. [27]

Some people may be concerned about the electromagnetic interference between cell phones and medical devices. As recent information, patients, visitors and staff may use cell phones in any area of the hospital, as long as they are at least 1 meter from operating medical devices. [28]

Taking it into consideration that popularity of cell phone in Japan and the PDAs in the US, it seems that the future of smart phone is promising even in medicine. Also there is a business chance to expand mobile computer technology in medicine.

\section{Conclusion}

There has been a rapid expansion of computer use in medicine recently along with the diffusion of information technology in the US and Japan. There are a lot of pros and cons for computer use. Since governments promote computerization in medicine, if medical staff recognizes more benefits of computers, they can use them for improving safety and efficiency in medicine.

The use of mobile computer technology in medicine is much less prevalent in Japan as compared to the US. There is still a possibility to enhance medical education, clinical practice and patient safety by using such technology in Japan. In order to implement such mobile computer technology into medicine, more collaboration is necessary for both medical institutions and computer companies.

\section{Acknowledgement}

We thank Kimitaka Kaga, MD; Kiyoshi Kitamura, MD; Junji Otaki, MD; Hirotaka Onishi, MD; and other staff at the International Research Center for Medical Education, the University of Tokyo. They provided us an opportunity to give a joint seminar at the University of Tokyo, on May 25, 2005. This article is the revised version of the contents at the seminar. We also thank Thomas S. Inui, MD, and Shinichi Takamoto, MD for their suggestion concerning this collaborative work.

\section{References}

[1] S. Kaihara, "What is Medical informatics," Medical Informatics, vol.1, no.1, pp.8-19, 1996 (in Japanese).

[2] Z. Liu, T. Sakurai, T. Orii, T. Iga, and S. Kaihara, "Evaluation of Support Functions of the Prescription Order System in the University Hospitals," Proc. of
Joint Conference on Medical informatics, vol.15, no.1, pp.839-842, 1995 (in Japanese).

[3] T. Kiuchi, T. Sakurai, K. Ohe, Y. Ohashi, and S. Kaihara, "University Medical Information Network-Past, Present, and Future." Medinfo. 9, vol.1, pp.420424, 1998.

[4] M. Teranobu, H. Oki, S. Shimizu, M. Nakagawa, and M. Setoyama, "From a Viewpoint of Healthcare Information Administrator, Audit of Electronic Healthcare Information," Japanese Journal of Medical Informatics, suppl.2, pp.67-69, 2000 (in Japanese).

[5] IT Strategic Headquarters, Prime Minister of Japan and Cabinet, "e-Japan Priority Policy program," http://www. kantei.go.jp/foreign/it/network/ priorityall/index. html accessed Jul. 22, 2005.

[6] Committee for Healthcare Information System, "IT Ground Design for Healthcare System," http:// www.mhlw.go.jp/shingi/0112/dl/s1226-1.pdf accessed Jul. 22, 2005 (in Japanese).

[7] Statistics and Information Department, the Ministry of Health, Labor and Welfare, "Static and Dynamic Statistics of Medical Institutions,"

http://www. mhlw.go.jp/toukei/saikin/hw/iryosd/02/ index.html

accessed Jul. 22, 2005 (in Japanese).

[8] The Information and Communication Technology, International Telecommunication Union (ITU), "ITU Telecommunication Indicators in 2002,"

http://www. itu.int/ITU-D/ict/statistics/at_glance/ Internet02. pdf

accessed Jul. 22, 2005.

[9] K. Terry, "Computer Consult: Beam it up, Doctor," Medical Economics, vol.79, no.4, pp. 34-36, 2002.

[10] J. Watanabe, S. Natsuzumi, Y Mizuguchi, E. Ohtsuki, T. Nakano, and H. Kihara, "Experiments on security of wireless network for medical use," Japan Journal of Medical Informatics, vol.24, no.1, pp.187-192, 2004 (in Japanese).

[11] Japana Centra Revuo Medicina, "Database of Japana Centra Revuo Medicina," http://www.jamas.or.jp/ database.htm accessed Jul. 22, 2005 (in Japanese).

[12] Japan Council for Quality Health Care, "Medical Information Network Distribution Service," http:// minds.jcqhc.or.jp accessed Jul. 22, 2005 (in Japanese).

[13] The Pharmaceuticals and Medical Devices Agency, "Information on Approved New Drugs,"

http://www.info.pmda.go.jp/shinyaku/shinyaku_ index.html accessed Jul. 22, 2005 (in Japanese).

[14] The Pharmaceuticals and Medical Devices Agency, "Information about Prescription Drug Package Insert," http://www.info.pmda.go.jp/info/pi_index.html accessed Jul. 22, 2005 (in Japanese). 
[15] National Digital Library, "Health Education Assets Library (HEAL)," http://www.healcentral.org accessed Jun. 24, 2005.

[16] Up-To-Date, "Up-To-Date online," http:// www.uptodate.com/, accessed Jul. 22, 2005.

[17] Epocrates, "Epocrates," http://www.epocrates. com accessed Jul. 22, 2005.

[18] The Statistics Bureau in the ministry of internal affairs and communications, "Survey of Household Economy, Items Related to Information Technology," http://www.stat.go.jp/english/data/ joukyou/2004ni/ index.htm accessed Jul. 22, 2005.

[19] Japan Association for Medical Informatics, "Japanese Journal of Medical Informatics," suppl.5, CD-ROM, Tokyo, 2004 (in Japanese).

[20] E. Kimura, Y. Onozaki, and Y. Shizui, and M. Ohnishi, "Development of nursing care support system using PDA with wireless and barcode reader," Annual Symposium Proceedings/AMIA Symposium, p.894, 2003.

[21] Healthcare Information and Management Systems Society, "2002 HIMSS/AstraZeneca Clinician Survey," http://www.himss.org/content/files/surveyresults/ Final\%20Final\%20Report.pdf accessed Jul. 22, 2005.

[22] D.W. Bates, M. Cohen, L.L. Leape, J.M. Overhage, M.M. Shabot, and T. Sheridan, "Reducing the frequency of errors in medicine using information technology," Journal of the American Medical Informatics Association, vol. 8, no.4, pp. 299-308, 2001.

[23] R.N. Shiffman, M. Freudigman, C.A. Brandt, Y. Liaw, and D.D. Navedo, "A guideline implementation system using handheld computers for office management of asthma: effects on adherence and patient outcomes," Pediatrics, vol.105, no.4, pt.1, pp.767-773, 2000.

[24] S.B. Bird, R.S. Zarum, and F.P. Renzi, "Emergency medicine resident patient care documentation using a hand-held computerized device," Academic Emergency Medicine, vol.8, no.12, pp.1200-1203, 2001.

[25] D. Szynal, "PDAs come in handy," Health Data Management, vol.9, no.8, pp.18-20, 2001.
[26] G.M. Leung, J.M. Johnston, K.Y. Tin, I.O. Wong, L.M. Ho, W.W. Lam, and T.H. Lam, "Randomised controlled trial of clinical decision support tools to improve learning of evidence based medicine in medical students," British Medical Journal, vol.327, no.7423, pp.1090-1095, 2003.

[27] PressPass in Microsoft, "Microsoft Releases Windows Mobile 5.0.,"

http://www.microsoft.com/ presspasspress /2005 /may 05 /05-10WindowsMobile5PR.mspx accessed Jul. 22, 2005.

[28] N. Lawrentschuk and D.M. Bolton, "Mobile phone interference with medical equipment and its clinical relevance: a systematic review," Medical Journal of Australia, vol.181, no.3, pp.145-149, 2004.

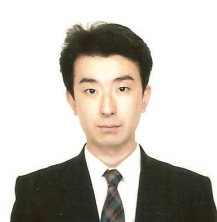

\section{Daisuke KOIDE}

Daisuke KOIDE has been an associate professor at the University of Tokyo since 2003. He received B.A. in pharmaceutical science from Tokyo University of Science in 1991, and Master and Ph.D. in Health Science from the University of Tokyo in 1993 and 1996 respectively. His research interests are medical informatics and pharmacoepidemiology. He is also a director of the Drug Safety Research Unit and a councilor of Japanese Society for Pharmacoepidemiology. He was awarded a bronze medal at the 11 th triennial congress Medinfo2004 in San Francisco; the international meeting for the medical informatics in 2004.

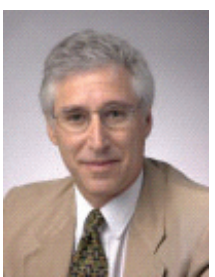

\section{Edward PESKIN, MD}

Edward PESKIN,MD is a US Board Certified Obstetrician/Gynecologist and an Associate Professor of Clinical Obstetrics and Gynecology at the University of Massachusetts Medical School which is located in Worcester, Massachusetts, USA His interest in medical informatics comes from his work with medical students and in his role as a member of the Undergraduate Medical Education Committee of the US Association of Professors of Gynecology and Obstetrics, an organization devoted to medical education issues. His involvement in Japanese medical education occurred in the spring of 2005 when he served as a visiting professor of medical education at the University of Tokyo. 


\section{Appendix 1}

\section{ComputerApplications For Teaching and Clinical Care - Japanese}

\section{Desktop applications}

\section{Electronic clinical guidelines}

http://minds.jcqhc.or.jp/to/index.aspx Medical Information Network Distribution Service (Minds) http://www.mnc.toho-u.ac.jp/mmc/guideline/index.htm Library, Toho Medical University

\section{Electronic textbooks}

http://www.banyu.co.jp/merck/index.html Merck Manuals http://www.ibaraisikai.or.jp/treasure/chisivew/chisiki.html Knowledge of Internal Medicine http://www.kanazawa-med.ac.jp/ hasumura/ A Physical Examination Skills http://next.bml.co.jp/diagnosis/contents.html diagnosis on Web / Contents http://www.kanazawa-med.ac.jp/ htogkmu/msnote.html Ob/Gyn HyperText for Medical Students http://www.qent.med.kyushu-u.ac.jp/virtual.html Virtual Otolaryngology Hospital http://www2.kpu-m.ac.jp/ picu/ Pediatric ICU Manual http://cancerinfo.tri-kobe.org/ Cancer Information Japan (PDQ,etc) http://www.srl.info/index.html Clinical laboratory http://www.hamt.or.jp/KENSA/MSTAFF/ECG/ecg.html Electrocardiogram ECG http://www.jichi.ac.jp/usr/cpth/us./us.home.html Ultrasound http://web.kanazawa-u.ac.jp/ med23/NMImageConf.html Nuclear Medicine Imaging Conference http://web.sc.itc.keio.ac.jp/anatomy/anatomy/anatomy.html anatomy http://www.lib.kobe-u.ac.jp/products/anatomy/index.html anatomy http://bme.ahs.kitasato-u.ac.jp/qrs/phy/index.html Physiology http://pharma1.med.osaka-u.ac.jp/textbook/Pharm-Textbook.html Pharmacology 1 http://pharma1.med.osaka-u.ac.jp/textbook2/Pharm-Textbook2.html Pharmacology 2

\section{Electronic journals}

http://e-medicine.sumitomopharm.co.jp/e-medicine/index2.html Journal Watch http://www.nankodo.co.jp/yosyo/user/html/ New England Journal of Medicine

\section{Drug information}

http://www.info.pmda.go.jp/ Pharmaceutical and Medical Devices Information (PMDA) http://mid.cc.kumamoto-u.ac.jp/top.html Drug Package Insert http://www.nihs.go.jp/dig/jindex.html Drug Info Guide http://bme.ahs.kitasato-u.ac.jp:8080/docs/ts/html/note/index.html Drug Information for Patients http://www.jah.ne.jp/ kako/ Emergency Drug information http://www.j-poison-ic.or.jp/homepage.nsf Japan Poison Information Center http://center.umin.ac.jp/cgi-open-bin/hanyou/lookup/search.cgi?parm=POISON UMIN Poison Database

\section{Medical laws}

http://law.e-gov.go.jp/cgi-bin/idxsearch.cgi Database of laws and regulations http://web.kyoto-inet.or.jp/org/kanpo/3W/houki/houritu.html Medical laws, etc.

\section{Medical writing}

http://www.sunmedia.co.jp/kitei.html\#A Instructions for Authors Domestic http://www.toukoukitei.net/index.html Instructions for Authors Oversea http://www.biwa.ne.jp/ fumika/eiyou.htm English writing support http://mhlw-grants.niph.go.jp/ MHLW Grants System

\section{Micellaneous} http://s2001.medic.mie-u.ac.jp/icd/ ICD 10 and DPC (Diagnosis Procedure Combination) coding 
http://lsd.pharm.kyoto-u.ac.jp/ja/index.html Medical and Pharmaceutical dictionaries http://www.sam.hi-ho.ne.jp/tootake/yougo2.htm Medical and Pharmaceutical dictionaries http://di.m-pharma.co.jp/foreign/index.html Foreign Language Conversation in Hospital and Pharmacy http://food.tokyo.jst.go.jp/index.html Food Composition Database http://www.geocities.jp/kazu_hiro/index.html Nursing Site

\section{PDA sites}

\section{Software}

http://www.medicalview.co.jp/stedman/stedman03.shtml STEDMAN'S Medical Dictionary http://www.m2plus.com/mproducts/05pda/pda.html Drug information 2005 for PDA http://www.m2plus.com/mproducts/resident/resident.html The Resident http://www.m2plus.com/mproducts/migiude/migi1-2.html Mr. Reliable Vol. 1/2 (Introduction) http://www.geocities.jp/palmpro/HOW/HOWDRUG.HTM DoseSpeed Ver.8.0 http://www.geocities.jp/palmpro/HOW/HOWMEDUNIT.HTM Medical Unit Converter http://www.nextftp.com/moritaro/Develop/Dev-Acd.html Acid-Base for Palm http://www006.upp.so-net.ne.jp/kono/BSACalc.htm BSA Calculator

\section{Link sites}

http://www5.ocn.ne.jp/ palm-med/ Palm Med \& Pharma

http://unoubeya.main.jp/ Right Brain $\wedge^{\wedge}$ Room

http://www.lab.toho-u.ac.jp/med/peds/link2/ Palm user's links for medical professionals 
Appendix 2

ComputerApplications For Teaching and Clinical Care -English

\section{Desktop applications}

http://www.healcentral.org Central data site for many multimedia programs some with voice and thousands of images for medical student education in the basic sciences and clinical areas. Site is run by three US medical school with a government grant and is free and open to the public including international medical schools. There are a few Japanese language patient education documents. Excellent site for medical education, and the best I have seen so far.

Heal Local System for Individual Medical School-in testing phase-available sometime in 2005 . contact bas@mednet.ucla.edu. if interested in participating. Will have any information needed from "heal" site plus local University information with local control of the site. It is being created to fit into international computing standards. University of Tokyo could consider running such a site and possibly sharing it with other medical schools. Alternatively, Japan Ministry of Education could consider running such a site for all Japanese medical schools with a mixture of English language and Japanese language programs.

www.nlm.nih.gov National Library of Medicine has medline plus which is English and Spanish Language Patient Information including animation and voice

http://www.umassmed.edu/strokestop/module_one/module_fr.html This is the free program from the University of Massachusetts that Dr. Peskin demonstrated to teach neuro-anatomy and neuro-physiology. It is not a protected document and you are welcome to use it

http://www.med-ed-online.org An American on-line medical education journal. Go to resources for multimedia educational programs

http://www.msu.edu/user/inetproj/homepage5.html American med-school with a number of on-line curricula including how to use the internet for medical education

http://www.epocratesonline.com on line US drug reference with excellent drug interaction feature, and including non-prescription drugs, and herbal medications. There is also a pill identifier for patients using an unknown medication, tables, alerts on drug adverse reactions or major medical news of clinical importance. It is updated weekly. You may try it free for one month and is \$US59 per year. Problem for Japanese physicians is that it is US medications. Dr. Peskin contacted them and they have no plans for a Japanese language version soon. Japan could benefit greatly from a program like this with the program for drug interactions being most useful.

http://mycourses.med.harvard.edu/vp_view.asp?frame=Y\&tracking=Y\&case_id=\{B517ED16-BFB1-4856-B20712F9623B539D\}

continuing medical education/ available for anyone but not free

http://cme.nejm.org/

continuing medical education based on the New England Journal of Medicine articles

\section{PDA(PERSONAL DIGITAL ASSISTANT) APPLICATIONS}

-FOR THOSE JAPANESE PHYSICIANS WHO WOULD LIKE TO START USING PDAS NOW

-FOR THOSE JAPNESE PHYSICIANS WHO WILL WAIT AND BUY A

CELL PHONE-PDA COMBINATION DEVICE, AND WILL NEED 


\section{THIS INFORMATION WHEN THEY MAKE THAT PURCHASE}

WHICH PDA TO BUY, YOU MUST FIRST DECIDE-Which operating system (software system that runs the machine) to use (current choices):

Palm OS-runs on devices made by companies such as Palm and Handspring Advantages: small, lightweight, comfortable to carry with you. Less Expensive, Lots of Medical Software. Long battery life. Disadvantages: Does not easily merge with all Microsoft desktop applications. Is losing market share and medical applications may not be as plentiful and well supported in the future. For example, Sony currently makes these but is stopping production for the Japanese market.

Pocket PC (being discontinued and replaced by Mobile 5 so you can buy a current Pocket PC or wait a short time for Japanese mobile 5 PDAs) Runs on devices made by Hewlett Packard, Compaq, and Casio. Advantages: Larger with bright color screens so easier to see, coordinates with Windows functions very well, Disadvantages: More Costly, Larger size makes them less comfortable to carry with you, less medical software available but quickly catching up with PalmOS devices.

Mobile 5-Sharp and Samsung are coming out with devices soon for the Japanese market. Will be used to combine cell phones and PDA. This may be what is needed to get large numbers of Japanese physicians to use PDAs for medical applications.

PDA Buyer's Guide: www.epinions.com; www.barginpda.com, www.cnet.com

\section{WHERE TO GET MEDICAL PROGRAMS THAT YOU WANT TO USE ON YOUR PDA}

- www.handango.com: leader in medical software

- http://pbrain.hypermart.net/: Great source for medical PDA info, software, news

- www.zdnet.com site with software \& hardware reviews, comparison buying, more

Utilities: (only needed for some programs. in my opinion, only useful for advanced users)

Adobe Acrobat: http://www.adobe.com/products/acrobat/readerforpalm.html

Medical Calculator: http://www.doctorsgadgets.com/software/free-pda-drug-reference.htm

Treatment Guidelines/References:

Am Coll. of Cardiology Guidelines: http://www.acc.org/clinical/palm_downloadstep1.htm

Asthma NHLBI Guideline: http://www.aafp.org/x28143.xml

Breast Cancer Prediction Tool: http://smi-web.stanford.edu/people/pcheng/breastca/

Cholesterol ATP III Calculator: http://hin.nhlbi.nih.gov/atpiii/atp3palm.htm

Current Clinical Strategies (Book/PDA Out \& In-Pt, Medicine, HIV, CCU, Psychiatry, Peds) http:// ccspublishing.com/ccs/ (\$15-25/book, $\$ 50$ for all in the series)

Evidence Based Pearls: www.handango.com; search "Evidence Based Practice" (\$19.95/year)

(Dr. Frank Domino, Associate Professor at the University of Massachusetts, who helped prepare some of the PDA information in this handout, has a financial interest in Evidence Based Pearls)

Immunizations: http://www.immunizationed.org/anypage.aspx?pagename=shotshome 
Medical Decision Tools (MedRules): http://pbrain.hypermart.net/medrules.html

OB Wheel: http://www.fppda.com/timobppc.htm

\section{Drug Databases}

Epocrates Drug Database: http://www2.epocrates.com/products/os/rx_subs.html Three choices:

"Essentials" Most expensive and complete. (\$US139/year)

Most popular drug reference in the US. Dr. Peskin's favorite. Includes information on diagnosis of a large number of diseases, commonly used tables, US used medications including prescription, nonprescription, and herbal medications. Most useful is ability to check for up to 30 drug interactions. Also has infectious disease information, lab information, automatic alerts for warnings about drugs or very important news concerning medical issues. Updated weekly. Is inexpensive relative to "Up To Date" partly due to this private company taking money from drug companies. Dr. Peskin finds it reliable but there is the potential for conflict of interest.

Problem for Japanese physicians is that it is based on US drugs. In Dr. Peskin's opinion, a PDA version in Japan is very likely to reduce medication errors and drug interactions, and to lead to more correct diagnoses.

"RxPro" (just Drug and Diagnosis Information: \$59/year) Excludes the laboratory information.

"Rx" (just Drug information. Free. Great for medical students and others who need to limit their expenses

\section{PDA Resource Pages}

Ectopic Brain: http://pbrain.hypermart.net/

Medical Student PDA Café: http://www.medstudentcafe.com/pdacenter.htm

Text-Like Apps

InfoRetriever-EBM Abstracts, Cochrane, POEMS, Practice Guidelines (Pocket PC) \$250.00

$\circ$ www.infopoems.com (\$249.00 per year)

- HanDBase-database application; download free applets or write your own; On-Call; $\$ 30.00$ www.handango.com

- UpToDate - full database of web version, free with subscription (\$400-500) www.uptodate.com (In Dr. Peskin's opinion, too expensive, and the drug information is not as useful as Epocrates for US Physicians. The drug information has even less usefulness for Japanese physicians. Diagnostic information may be useful for residents in specialties where they are in and out of operating room and do not have easy access to desk-top computers.)

- SkyScape : 5 Minute Clinical Consult, FerriGuide, etc. Abridged Textbooks (part of Epocrates Essential) www.handango.com

Electronic Medical Records

- Patient Tracker - www.handheldmed.com; Intuitive, FREE, desktop for \$300

- PatientKeepter-Biggest, \$35-40; Enterprise Option (busy for me)

- Handbase Patient Tracker Applet-Free, Simplistic

Web Resources on PDA's

Ectopic Brain: http://pbrain.hypermart.net/: Great source for medical PDA info, apps, news 
UT HSC SA: http://www.library.uthscsa.edu/internet/pda.cfm good links

-Counseling Tools:

Smoking Cessation: http://www.smokefree.gov/hp-hcsit.html

Preventive Services: http://pda.ahrq.gov/index.html 